$09 ; 13 ; 15$

\title{
Исследование потерь пропускания в поликристаллическом CVD-алмазе в миллиметровом диапазоне длин волн методом свободного пространства
}

\author{
() Д.Л. Гнатюк ${ }^{1}$, А.В. Зуев ${ }^{1}$, Д.В. Крапухин ${ }^{1}$, П.П. Мальцев ${ }^{1,2}$, Д.Н. Совык ${ }^{3}$, В.Г. Ральченко ${ }^{3}$ \\ ${ }^{1}$ Институт сверхвысокочастотной полупроводниковой электроники им. В.Г. Мокерова РАН, Москва, Россия \\ ${ }^{2}$ МИРЭА - Российский технологический университет, Москва, Россия \\ ${ }^{3}$ Институт общей фризики им. А.М. Прохорова РАН, Москва, Россия \\ E-mail: dgnatyuk@yandex.ru
}

Поступило в Редакцию 2 июня 2021 г.

В окончательной редакции 2 июня 2021 г.

Принято к публикации 15 июня 2021 г.

Исследованы структура и пропускная способность пластин поликристаллического CVD-алмаза диаметром до $75 \mathrm{~mm}$ в диапазоне частот $50-67 \mathrm{GHz}$ методом свободного пространства. Показано, что величина тангенса угла диэлектрических потерь $\tan \delta$ лежит в диапазоне $7.5 \cdot 10^{-3}-8 \cdot 10^{-2}$, возрастая с частотой, а потери пропускания составляют порядка $1 \%$.

Ключевые слова: миллиметровый диапазон длин волн, поликристаллический алмаз, радиопрозрачность.

DOI: 10.21883/PJTF.2021.18.51473.18900

Значительное внимание к оптическим свойствам алмаза, выращиваемого из газовой фазы (chemical vapor deposition, CVD), в миллиметровом диапазоне длин волн связано с поиском новых материалов для выходных окон сверхмощных (класса $1 \mathrm{MW}$ ) гиротронов непрерывного действия, генерирующих излучение на частоте $170 \mathrm{GHz}[1]$. Имеются экспериментальные данные по исследованию прозрачности поликристаллических алмазов на частотах $f$ вплоть до $1 \mathrm{THz}[2-6]$. В наиболее качественных алмазных дисках измерены величины тангенса угла диэлектрических потерь $\tan \delta$ порядка $10^{-5}[2,3]$, что соответствует низкому (порядка $10^{-3} \mathrm{~cm}^{-1}$ ) коэффициенту поглощения. С уменьшением частоты прозрачность падает из-за возрастающего вклада в проводимость свободных носителей заряда, источником которых считаются дефекты и границы в алмазе [3]. Область частот ниже $100 \mathrm{GHz}$ исследована слабее и отличается большим разбросом экспериментальных данных: в диапазоне $15-111 \mathrm{GHz}$ получены величины $\tan \delta$ от $\sim 10^{-3}$ до $3 \cdot 10^{-5}[4-8]$. Диапазон частот $50-70 \mathrm{GHz}$ (пятимиллиметровый диапазон длин волн) представляет практический интерес в связи с возможностью передачи больших объемов информации с высокой скоростью в широкой полосе, в том числе с использованием систем пятого поколения мобильной связи $5 \mathrm{G}(66-71 \mathrm{GHz})$. Алмаз с его высокой теплопроводностью и широким спектральным окном прозрачности является перспективным материалом для изготовления не только радиопрозрачных крышек излучателей, но и теплопроводящих корпусов. В настоящей работе представлены результаты измерений радиопрозрачности поликристаллических алмазов в диапазоне частот 50-67 GHz.

Две пластины поликристаллического алмаза диаметром $57 \mathrm{~mm}$ и толщиной $366 \mu \mathrm{m}$ (образец $A$ ) и диаметром $73 \mathrm{~mm}$ и толщиной $450 \mu \mathrm{m}$ (образец $B$ ) синтезировались в СВЧ-плазмохимическом реакторе ARDIS-100 (OOO „Оптосистемы“, частота $2.45 \mathrm{GHz}$ ) в смеси метан-водород. Алмазные пластины выращивались на полированной подложке из монокристаллического кремния толщиной $3 \mathrm{~mm}$. Образец $A$ получен при следующих параметрах процесса синтеза: содержание метана в смеси $\mathrm{CH}_{4}-\mathrm{H}_{2}$ составляло $2.5 \%$, давление 100 Torr, температура подложки $820^{\circ} \mathrm{C}$, скорость осаждения $\sim 3 \mu \mathrm{m} / \mathrm{h}$. Условия роста непрозрачного в видимом диапазоне образца $B$ отличались: концентрация $\mathrm{CH}_{4}$ в смеси 5\%, давление 50 Torr, температура подложки $720^{\circ} \mathrm{C}$, скорость осаждения $\sim 1.5 \mu \mathrm{m} / \mathrm{h}$. Общий расход газа в обоих процессах был равен $400 \mathrm{sccm}$. Отделенная от подложки алмазная пластина была получена химическим травлением $\mathrm{Si}$ в смеси $\mathrm{HF}+\mathrm{HNO}_{3}$. Изображения ростовой (крупнозернистой) поверхности образца $A$ в растровом электронном микроскопе (РЭМ) (рис. 1) выявляют типичную топографию поликристаллического алмаза с хаотически ориентированными ограненными зернами. Размер кристаллитов в центре образца составляет в среднем $\sim 130 \mu \mathrm{m}$ в поперечнике (рис. $1, a$ ), но постепенно уменьшается по мере удаления от центра до $\sim 50 \mu \mathrm{m}$ на краю диска (рис. 1,c). Также вдоль радиуса меняется и текстура поверхности, на периферии появляется все больше граней (100), растет количество двойников на гранях (111). Величина среднеквадратичного значения шероховатости $R_{r m s}$ на ростовой стороне образца $A$, измеренная на оптическом профилометре NewView 5000 (ZYGO), находилась в диапазоне 3-8 $\mu \mathrm{m}$, уменьшаясь к краю диска. На противоположной гладкой стороне, прилегающей к подложке, шероховатость составляла порядка $10 \mathrm{~nm}$. Для образца $B$ получены близкие значения. Оценки показали, что шероховатость 


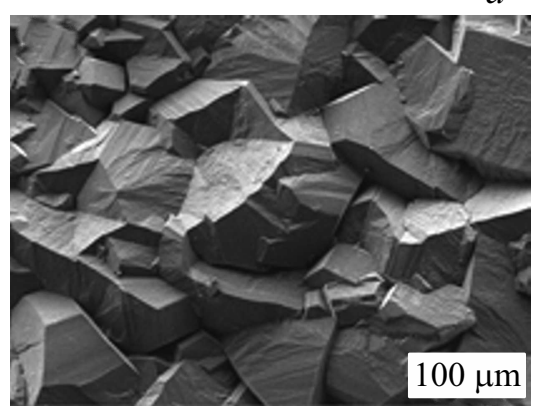

$b$

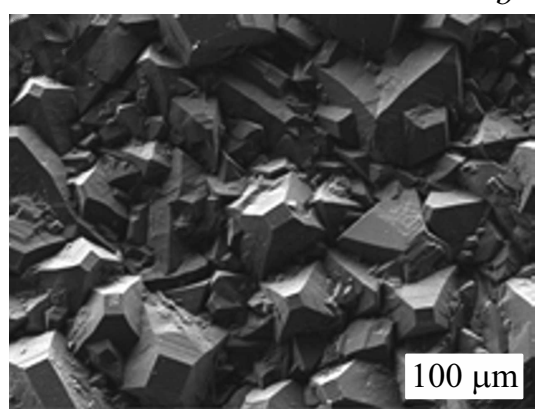

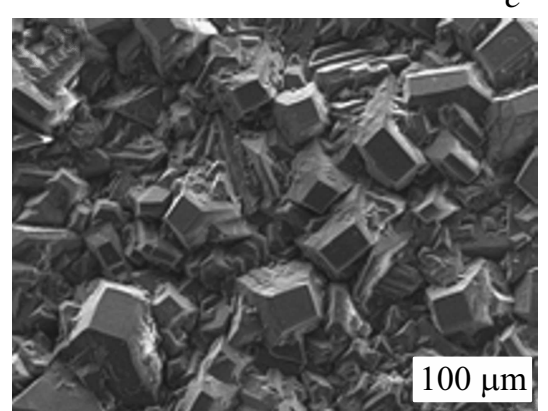

Рис. 1. РЭМ-изображения ростовой поверхности алмазной пластины диаметром $57 \mathrm{~mm}$ (образец $A$ ): в центре пластины $(a)$, на расстоянии $14 \mathrm{~mm}$ от центра $(b)$ и у края пластины $(c)$.

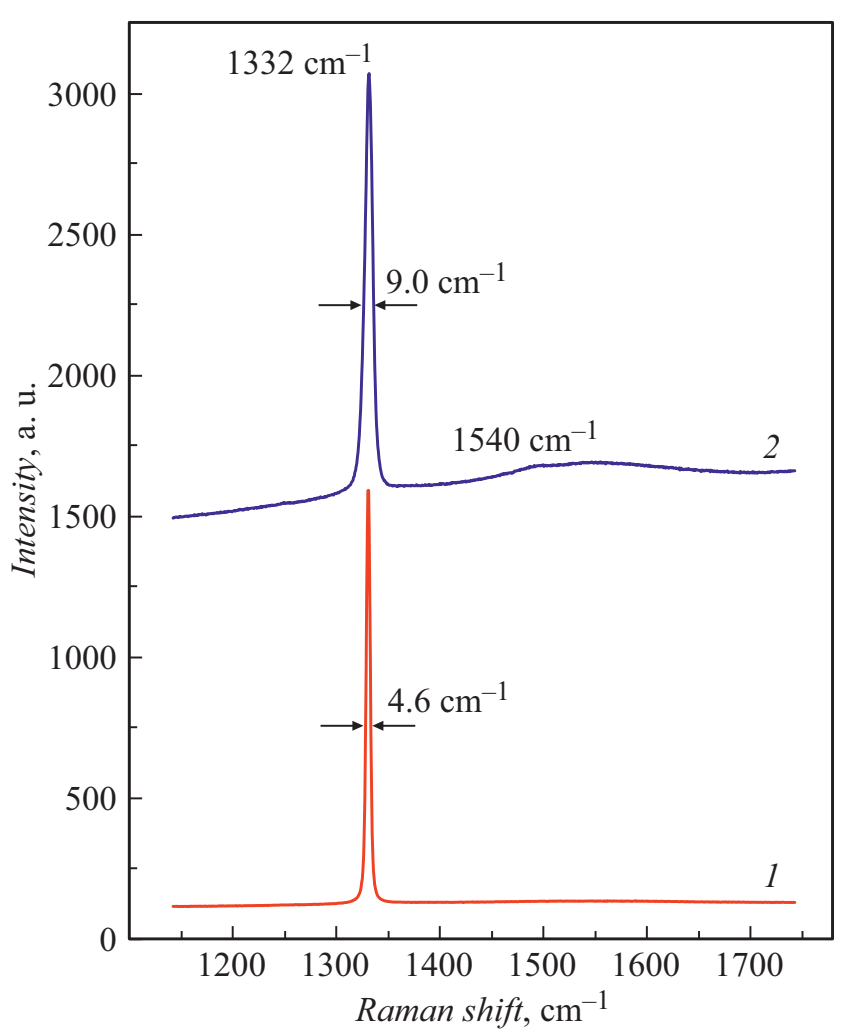

Рис. 2. Спектры КР, измеренные в центре поликристаллической алмазной пластины (образец $A$ ) на ростовой стороне $(1)$ и на подложечной стороне (2).

поверхности не должна приводить к существенному рассеянию СВЧ-излучения на частотах 50-67 GHz, которым соответствует длина волны $\lambda \approx 6-4.5 \mathrm{~mm}$. Считается, что рассеянием можно пренебречь, если отношение $R_{r m s} / \lambda<0.05$. В данном случае $R_{r m s} / \lambda<0.0017$, поэтому полировка пластин для измерений поглощения не являлась необходимой.

Структура поликристаллического алмаза анализировалась методом спектроскопии комбинационного рассеяния (КР) света на спектрометре LabRam HR800. Pacсеяние света возбуждалось лучом полупроводникового лазера на длине волны $473 \mathrm{~nm}$, который фокусировался на поверхность образца в пятно диаметром около $1.5 \mu \mathrm{m}$. На рис. 2 показаны спектры КР, измеренные с двух сторон в центре пластины: на крупнозернистой ростовой стороне и прилегающей к подложке стороне алмаза с субмикронными зернами. На ростовой стороне наблюдается узкий пик на частоте $1332 \mathrm{~cm}^{-1}$, принадлежащий алмазу. Другие фазы углерода в спектре отсутствуют, что подтверждает довольно высокое качество алмазного диска. Ширина пика КР в спектрах, записанных вдоль радиуса на различном удалении от центра образца, лежала в пределах $4.6-6.0 \mathrm{~cm}^{-1}$. Иная картина выявлена в спектрах, измеренных на мелкозернистой подложечной стороне: помимо уширенного алмазного пика $1332 \mathrm{~cm}^{-1}$ регистрируется широкая слабая полоса с центром при $1540 \mathrm{~cm}^{-1}$, вызванная включениями аморфного углерода (рис. 2).

Измерения потерь пропускания электромагнитных волн при прохождении через алмазную пластину проводились методом свободного пространства. Метод не налагает жестких требований на геометрическую форму исследуемого образца: он должен быть лишь плоским с известной толщиной в пределах $\lambda / 18-\lambda$. Для минимизации погрешности измерений, обусловленной эффектами дифракции на краях образца, его поперечный размер должен быть не менее трех ширин диаграммы направленности антенны (ДНА) по уровню $3 \mathrm{~dB}$ в $E$-плоскости (в плоскости вектора электрического поля). Схема установки показана на рис. 3, $a$. Исследуемая пластина (1) размещалась по центру между рупорными антеннами с фланцем WR-15 (2). Расстояние между антеннами составляло $143 \mathrm{~cm}$, что обеспечивало нахождение образца в дальней зоне антенн во всем исследуемом диапазоне частот. На удалении $72 \mathrm{~cm}$ от антенны поперечный размер ДНА составлял $10 \pm 1.3 \mathrm{~cm}$, что превышало диаметр алмазных дисков, поэтому использовался радионепроницаемый экран (3) с отверстием, равным диаметру диска. Антенны с помощью коаксиально-волноводных переходов (КВП) и кабельных сборок (4) подключались к векторному анализатору цепей Keysight с рабочим диапазоном частот от $10 \mathrm{MHz}$ до $67 \mathrm{GHz}$ (5). 


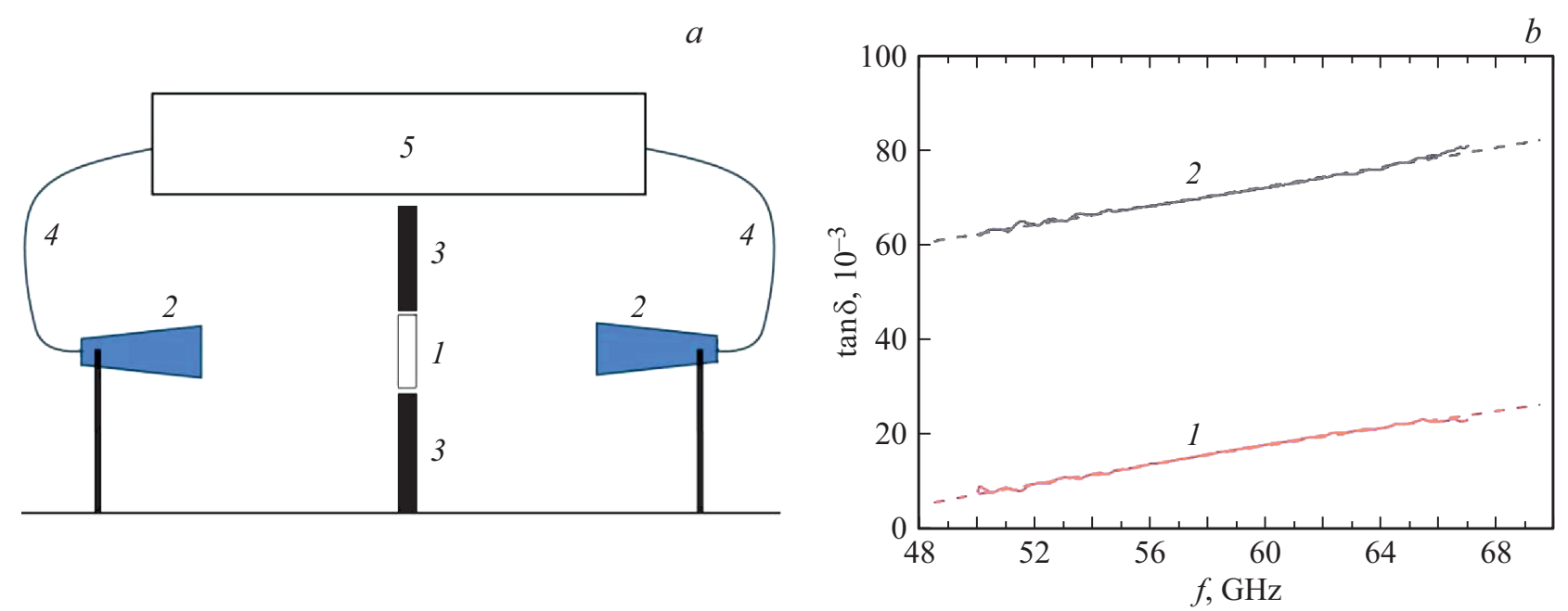

Рис. 3. $a$ - схема экспериментальной установки для измерения СВЧ-поглощения: 1 - измеряемый образец, $2-$ антенна, 3 - экран, 4 - кабельная сборка с КВП, 5 - векторный анализатор цепей; $b$ - частотные зависимости тангенса угла потерь для алмазных дисков диаметром 57 (1) и $73 \mathrm{~mm}$ (2). Штриховые линии - аппроксимации по формуле (1).

Для определения величины $\tan \delta$ использовалось программное приложение N1500A к анализаторам цепей Keysight для измерения свойств материалов, в котором применяется методика калибровки в свободном пространстве GRL (стробирование, отражение, линия). Вычисления величин $\varepsilon^{\prime}$ и $\tan \delta$ проводились методом Reflection/Transmission Epsilon Precision (NIST Precision) на основе измеренных $S$-параметров. Величина $\varepsilon^{\prime}$ составила $\sim 5.7$. Зависимости $\tan \delta$ от частоты, представленные на рис. $3, b$, демонстрируют монотонный рост потерь с частотой. На частоте $50 \mathrm{GHz}$ величина $\tan \delta$ для пластин $A$ и $B$ составила $7.5 \cdot 10^{-3}$ и $6.1 \cdot 10^{-2}$ соответственно, а на $67 \mathrm{GHz}$ эти величины возрастают до $2.2 \cdot 10^{-2}$ и $8.0 \cdot 10^{-2}$. Экспериментальные зависимости $\tan \delta(f)$ могут быть аппроксимированы выражением $[3,8]$ :

$$
\tan \delta=a / f+b f,
$$

где коэффициент $a=\sigma /\left(2 \pi \varepsilon^{\prime} \varepsilon_{0}\right), \sigma$ - электрическая проводимость, $\varepsilon_{0}$ - диэлектрическая проницаемость вакуума, $b-$ константа, пропорциональная концентрации дефектов решетки алмаза. Первый член в уравнении описывает потери за счет проводимости, а второй потери, вызванные однофононным возбуждением акустических колебаний на дефектах решетки. В случае поликристаллических алмазов высокого качества (частично прозрачных в оптическом диапазоне) в диапазоне $50-200 \mathrm{GHz}$ величина $\tan \delta$ снижается с частотой примерно пропорционально $1 / f$ [3]. Для сильно дефектных алмазных пластин в работе [8] наблюдалась обратная тенденция, а именно увеличение потерь с ростом частоты в диапазоне $24-30 \mathrm{GHz}$, что соответствует доминированию второго члена в формуле (1), как и в нашем эксперименте. Наилучшая подгонка измеренных кривых $\tan \delta(f)$ по формуле (1) привела к следующим коэффициентам: $a_{1}=-1.20 \mathrm{GHz}$ и $b_{1}=6.23 \cdot 10^{-4} \mathrm{GHz}^{-1}$ для образца $A ; a_{2}=0.33 \mathrm{GHz}$ и $b_{2}=11.10 \cdot 10^{-4} \mathrm{GHz}^{-1}$ для образца $B$.

Механизмы возникновения потерь за счет проводимости и однофононного поглощения реализуются в основном в наиболее дефектном слое алмазной пленки. Аморфный углерод располагается преимущественно на границах зерен, поэтому для мелкозернистых алмазных пленок доля аморфной фазы может существенно возрастать. Первичный алмазный слой с субмикронными зернами, формирующийся на подложке кремния, представляет собой характерный пример такой структуры с повышенной дефектностью. С ростом дефектности увеличивается ширина алмазного пика на частоте $1332 \mathrm{~cm}^{-1}$, которая в спектре образца $A$ с мелкозернистой (подложечной) стороны достигала $9.0 \mathrm{~cm}^{-1}$, тогда как на крупнозернистой (ростовой) стороне ширина алмазного пика вдвое меньше (рис. 2). Включения электропроводного аморфного углерода в алмазной диэлектрической матрице обычно рассматриваются как основной источник потерь СВЧ-излучения в поликристаллическом алмазе $[2,3]$. Поликристаллический CVD-алмаз является градиентным материалом, и именно мелкозернистый подложечный слой в алмазной пластине обусловливает в значительной мере поглощение оптического и ИКизлучения [9]. Обогащенный дефектами подложечный слой может в значительной мере определять и величину второго члена в уравнении (1). Удаление дефектного слоя толщиной в несколько десятков или даже сотен микрометров механической или лазерной полировкой [9] может способствовать снижению СВЧ-потерь.

Измеренные минимальные значения $\tan \delta=7.5 \cdot 10^{-3}$ сопоставимы с экспериментальными данными для CVD-алмаза других авторов (см. таблицу), которые в диапазоне частот ниже $70 \mathrm{GHz}$ лежат в пределах $10^{-3}-5 \cdot 10^{-5}$. Заметим, что поглощение СВЧ-излучения в алмазе сильно зависит от структурного совершен- 
Литературные данные о диэлектрических свойствах поликристаллического CVD-алмаза на частотах ниже $70 \mathrm{GHz}$

\begin{tabular}{|c|c|c|c|c|}
\hline$f, \mathrm{GHz}$ & $\varepsilon^{\prime}$ & $\tan \delta$ & Метод & Лит. ссылка \\
\hline $\begin{array}{c}15 \\
22 \\
24,30 \\
27 \\
36,72 \\
50 \\
60\end{array}$ & $\begin{array}{c}5.7 \\
5.7 \\
5.5-5.6 \\
5.7 \\
5.66-5.83 \\
5.7 \\
-\end{array}$ & $\begin{array}{c}5 \cdot 10^{-4} \\
1.4 \cdot 10^{-3} \\
(1-8) \cdot 10^{-4} \\
(1.4-5.3) \cdot 10^{-3} \\
1.5 \cdot 10^{-4}, 0.7 \cdot 10^{-4} \\
7.5 \cdot 10^{-3} \\
5 \cdot 10^{-5}\end{array}$ & $\begin{array}{l}\text { CR } \\
\text { TE } \\
\text { CR } \\
\text { RR } \\
\text { OR } \\
\text { FS } \\
\text { FP }\end{array}$ & $\begin{array}{c}{[7]} \\
{[5]} \\
{[8]} \\
{[4]} \\
{[6]} \\
\text { Наст. раб. } \\
\text { [3] }\end{array}$ \\
\hline
\end{tabular}

Пр и м е ч ан и е. CR - цилиндрический резонатор; TE - резонатор с модой TE; RR - резонатор отражающего типа; OR - открытый резонатор; FS - метод свободного пространства; FP - резонатор Фабри-Перо.

ства синтезируемого материала и определяется технологией процесса выращивания. Коэффициент поглощения электромагнитной волны $\alpha$ связан с $\tan \delta$ соотношением $\alpha=\left(\pi \varepsilon^{\prime} f \tan \delta\right) / c$, где $f-$ частота, а $c-$ скорость света. В середине исследованного частотного интервала $(58 \mathrm{GHz})$ для образца $A$ характерна величина $\tan \delta=1.5 \cdot 10^{-2}$, что соответствует коэффициенту поглощения $\alpha=0.52 \mathrm{~cm}^{-1}$ и потерям в пропускании $1.3 \%$. Потери в пропускании порядка 1\% приемлемы при использовании алмазных пластин в качестве окон (крышек) в конструкциях с относительно невысокой СВЧ-мощностью.

\section{Благодарности}

Авторы выражают благодарность С.С. Савину за анализ образцов методом растровой электронной микроскопии, А.В. Инюшкину за помощь в обработке данных, компании Keysight Technologies и П.В. Байбакову за предоставление лицензий на приложение N1500A и опцию измерений во временно́й области для анализаторов цепей.

\section{Финансирование работы}

Работа выполнена при финансовой поддержке Российского фонда фундаментальных исследований (грант 19-07-00683).

\section{Конфликт интересов}

Авторы заявляют, что у них нет конфликта интересов.

\section{Список литературы}

[1] G. Gantenbein, A. Samartsev, G. Aiello, G. Dammertz, J. Jelonnek, M. Losert, A. Schlaich, T.A. Scherer, D. Strauss, M. Thumm, D. Wagner, IEEE Trans. Electron Dev., 61 (6), 1806 (2014). DOI: 10.1109/IVEC.2013.6571030

[2] Б.М. Гарин, В.В. Паршин, В.Г. Ральченко, В.И. Конов, А.Н. Копнин, А.Б. Мазур, М.П. Пархоменко, Е.Е. Чигряй, Письма в ЖТФ, 25 (7), 85 (1999).
[3] B.M. Garin, V.V. Parshin, S.E. Myasnikova, V.G. Ralchenko, Diamond Relat. Mater., 12 (10-11), 1755 (2003). DOI: 10.1016/S0925-9635(03)00199-7

[4] M.P. Parkhomenko, D.S. Kalenov, N.A. Fedoseev, I.S. Eremin, V.G. Ralchenko, A.P. Bolshakov, E.E. Ashkinazi, A.F. Popovich, V.K. Balla, A.K. Mallik, Phys. Wave Phenom., 23 (3), 202 (2015). DOI: 10.3103/S1541308X15030073

[5] J.M. Le Floch, R. Bara, J.G. Hartnett, M.E. Tobar, D. Mouneyrac, D. Passerieux, D. Cros, J. Krupka, P. Goy, S. Caroopen, J. Appl. Phys., 109 (9), 094103 (2011). DOI: $10.1063 / 1.3580903$

[6] R.S. Sussmann, J.R. Brandon, G.A. Scarsbrook, C.G. Sweeney, T.J. Valentine, A.J. Whitehead, C.J.H. Wort, Diamond. Relat. Mater., 3 (3-4), 303 (1994). DOI: 10.1016/0925-9635(94)90176-7

[7] A. Ibarra, M. Gonzalez, R. Vila, J. Molla, Diamond. Relat. Mater., 6 (5-7), 856 (1997). DOI: 10.1016/S0925-9635(96)00724-8

[8] Y.Q. Liu, M.H. Ding, J.J. Su, H. Ren, X.R. Lu, W.Z. Tang, Diamond. Relat. Mater., 73, 114 (2017). DOI: 10.1016/j.diamond.2016.08.007

[9] S.M. Pimenov, V.V. Kononenko, V.G. Ralchenko, V.I. Konov, S. Gloor, W. Lüthy, H.P. Weber, A.V. Khomich, Appl. Phys. A, 69 (1), 81 (1999). DOI: 10.1007/s003390050975 